\title{
Biological Markers and Response to Neoadjuvant Taxane-Based Chemotherapy in Patients with Locally Advanced Breast Cancer
}

\author{
Mohamed I. El-sayed, ${ }^{1}$ Doaa W. Maximous, ${ }^{2}$ Madeha M. Zakhary, ${ }^{3}$ and Nabiel N. H. Mikhail ${ }^{4}$ \\ ${ }^{1}$ Department of Radiation Oncology, South Egypt Cancer Institute, Assiut University, Assiut, Egypt \\ ${ }^{2}$ Department of Surgical Oncology, South Egypt Cancer Institute, Assiut University, Assiut, Egypt \\ ${ }^{3}$ Department of Biochemistry, Faculty of Medicine, Assiut University, Assiut, Egypt \\ ${ }^{4}$ Department of Biostatistics and Cancer Epidemiology, South Egypt Cancer Institute, Assiut University, Assiut, Egypt \\ Correspondence should be addressed to Nabiel N. H. Mikhail, nabiel.mikhail@gmail.com
}

Received 4 September 2012; Accepted 24 October 2012

Academic Editors: N. A. Franken and D. Mezzanzanica

Copyright ( $) 2012$ Mohamed I. El-sayed et al. This is an open access article distributed under the Creative Commons Attribution License, which permits unrestricted use, distribution, and reproduction in any medium, provided the original work is properly cited.

\begin{abstract}
Introduction. Biological markers as Her2/neu, p53, and hormonal receptors (HmRs) may be reliable parameters for prognostic assessment of patients of locally advanced breast cancer (LABC). This work aims at assessing the potential value of these biological markers for the prediction of disease outcome after neoadjuvant taxane-based chemotherapy and its implication on the surgical role. Patients and Methods. From March 2006 to September 2011, 95 patients with LABC were treated by neoadjuvant taxane-based chemotherapy given at intervals of 3 weeks. Expression of Her2/neu and p53 was examined in the initial tissue biopsy by using ELISA technique. Status of HmRs was determined using a commercial enzyme immunoassay. Three weeks after the third cycle, patients underwent surgical resection followed by 3 more cycles of taxane-based chemotherapy and radiotherapy as an adjuvant therapy. Relations of Her2/neu overexpression to p53, HmRs, and conventional prognostic factors were analyzed. Results. Median followup was 61 months. The 5-year DFS and OAS rates were significantly higher in patients with positive HmRs than in those with negative HmRs, patients with Her2 - than those with Her2+ breast cancer, and patients with intact p53 breast cancer than those with inactive p53. HER-2 overexpression was statistically significant associated with loss of HmR positive immunostaining $(P<0.0001)$, grade III breast cancer $(P<0.0001)$, advanced nodal status $(P=0.0039)$, and younger $(<50$ years $)$ age $(P=0.0108)$. Conclusion. Her $2 /$ neu overexpression was associated with poor DFS and OAS rates, as it was significantly associated with negative $\mathrm{HmR}$ and high grade.
\end{abstract}

\section{Introduction}

Neoadjuvant chemotherapy (NAC) is the standard of care in patients with locally advanced breast cancer (LABC) [1], as it improves local control and survival $[2,3]$. The reported clinical response rate to NAC varied between $30 \%$ and $90 \%$ and the 5-year overall survival (OAS) was reported to range between $40 \%$ and $60 \%$ [4]. As the clinical and pathological responses of breast cancer to NAC are shortterm markers for a long outcome, it is important to identify biological factors that may predict response to NAC and subsequent disease-free survival (DFS) and OAS [5, 6]. It is well established that the expression of the estrogen receptor (ER) and progesterone receptor ( $\mathrm{PR}$ ) determines the responsiveness of tumors to hormonal interventions.
Nevertheless the absence or presence of these hormonal receptors does not predict response to chemotherapy [7]. However, breast cancer patients with tumors that are ER positive and/or PR positive have lower risks of mortality after their diagnosis compared to women with ER- and/or PR-negative disease $[8,9]$. One of the most important markers being studied is Her2/neu protooncogene, which has been localized to long arm of chromosome and encodes a transmembrane tyrosine kinase growth factor receptor. The protein product of HER-2/neu is overexpressed in $25 \%-$ $30 \%$ of breast cancers [10] and is associated with a poor prognosis [11]. The tumor suppressor gene, p53, is located on short arm of chromosome 17. Mutations in the tumor suppressor gene p53 are present in 18\%-25\% of primary breast carcinomas [12]. Preclinical data have shown that 
cells with mutated p53 might be resistant to radiation or chemotherapeutics [13].

The aim of this study is to evaluate the potential value of biological markers (Her2/neu, p53, and hormonal receptor status) for the prediction of disease outcome and response to therapy in patients with locally advanced breast cancer, after neoadjuvant chemotherapy.

\section{Patients and Methods}

This prospective phase II study was conducted at South Egypt Cancer Institute, Assiut University, Egypt, and Sohag Cancer Centre, Sohag University, Egypt, during the period from March 2006 to September 2011. Informed consent was obtained for all patients, and the protocol was approved by institutional review board at our center.

2.1. Patients and Tumor Characteristics. This study included ninety-five female patients with biopsy proven locally advanced, nonmetastatic breast cancer (stage IIB (limited to T3N0) and stage IIIA disease), Eastern Cooperative Oncology Group performance score of 0 to 1, and left ventricular ejection fraction (LVEF) of $\geq 60 \%$. Each patient was subjected to clinical examination, laboratory investigations, and breast sonomammography to exclude multiple scattered microcalcifications. True-cut needle biopsy was taken for histopathological diagnosis and assessment of biological factors. Radiological studies were done, such as chest Xray and abdominopelvic ultrasonography to exclude patients with visceral metastasis and bone scan to exclude patients with bone metastasis. Each patient was given 3 cycles of taxenes based combination chemotherapy with 3 weeks interval, Paclitaxel $135 \mathrm{mg} / \mathrm{m}^{2}$, Adriamycin $50 \mathrm{mg} / \mathrm{m}^{2}$ and Cyclophosphamide $500 \mathrm{mg} / \mathrm{m}^{2}$. Three weeks after the third cycle, each patient was evaluated by clinical examination and breast sonomammography to assess the response to neoadjuvant chemotherapy. Primary end points were evaluation of the value of biological markers for the prediction of response to therapy and survival. Secondary end points were determination of the association of HER-2/neu overexpression in relation to p53 inactivation, hormonal receptor status, and conventional prognostic factors.

2.2. Evaluation of Biological Markers. After true-cut needle biopsy, the tissue samples were pulverized while frozen in a chilled mortar and homogenized for 2 minutes in TED buffer in melting ice using a Teflon homogenizer. These homogenates were centrifuged for 10 minutes at $10,000 \mathrm{xg}$ at $4^{\circ} \mathrm{C}$. The supernatants were recentrifuged at $3000 \mathrm{xg}$ for another 15 minutes and finally stored at $-70^{\circ} \mathrm{C}$ in $200 \mathrm{mi}$ aliquots till assay. Tissue levels of Her2/neu were determined by ELISA, using the human neu oncoprotein ELISA kit supplied by Oncogene Science Inc., OIA-04, Uniondale, New York, USA. For tissue homogenates, $100 \mu \mathrm{L}$ of tissue homogenate was extracted with $20 \mu \mathrm{L}$ of antigen extraction agent supplied with the kit. The tubes were centrifuged at $1500 \mathrm{xg}$ for 10 minutes. The supernatants were diluted 50 times with sample dilution buffer supplied in the kit. Then,
$100 \mu \mathrm{L}$ of diluted sample was used for the determination of Her2/neu. Tissue levels of p53 were also determined by ELISA technique, using kits supplied by Diaclone Research, France, Catalogue number 043. A monoclonal antibody specific for p53 had been coated onto the wells of the microtiter strips provided. During the first incubation, the p53 antigen was added to the wells. After washing, a biotinylated monoclonal antibody specific for p53 was incubated. Then the streptavidin-peroxidase enzyme was added. After incubation and washing to remove all unbound enzymes, a substrate solution which acts on the bound enzyme was added to induce a colored reaction product. The intensity of this colored product is directly proportional to the concentration of p53 present in the samples. Protein concentration in the tissue homogenates was determined by the method of Lowry et al. [14] as modified by Miller [15], whose method combines the Biuret and Folin Ciocalteu reactions [16]. The receptor status had been determined using a commercial enzyme immunoassay according to the instructions of the manufacturer (Abbott Laboratories, Chicago, IL, USA). A result exceeding $15 \mathrm{fmol} / \mathrm{mg}$ was considered positive for the presence of the particular receptor.

2.3. Assessment of Response. After neoadjuvant chemotherapy, patients with tumors $<5 \mathrm{~cm}$ in greatest dimension (objective response) underwent conservative breast surgery (excision of tumor with $2 \mathrm{~cm}$ rim of normal breast tissue and level I and II axillary dissection), whereas those with breast tumors $\geq 5 \mathrm{~cm}$ in greatest dimension (no response) or those with persistent positive surgical margins (after CBS) were subjected to MRM. Each patient in both groups was then given additional 3 cycles of taxanes-based combination chemotherapy followed by consolidative radiotherapy of 50 Gys with 2 Gys daily fraction to breast and chest wall using $3 \mathrm{D}$ radiation therapy planning (in patients who underwent CBS) and to chest wall using 2D radiation therapy planning (in patients who underwent MRM) by 2 parallel opposed tangential fields using $6 \mathrm{MV}$ photon beams. Supraclavicular irradiation (50 Gys/25 fractions/5 weeks) was given only to patients with positive axillary lymph nodes. A boost dose of 16 Gys in 8 fractions to tumor site using $12 \mathrm{Mev}$ electrons was given to patients who underwent conservative surgery.

All patients in this study were followed up monthly by clinical examination and every 3 months by sonomammography to diseased and healthy breasts, as well as by chest Xray and abdominopelvic ultrasound. At the end of followup, findings of Her $2 /$ neo expression, p53, and hormonal receptor status, were correlated for patients' response to neoadjuvant chemotherapy, and for 3-year DFS and OAS rates. Relation of Her2/neu over-expression to p53, hormonal receptor status and conventional prognostic factors was analyzed.

\section{Results}

The 95 cases included in the present study showed an age incidence which ranged from 33 to 72 years, with the median age of 48 years. In fifty-seven cases, $60 \%$ were of $<50$ years and the other 38 cases $(40 \%)$ were $\geq 50$ years of age. 
TABLE 1: Patients' characteristics.

\begin{tabular}{|c|c|c|}
\hline \multirow[t]{2}{*}{ Variable } & \multicolumn{2}{|c|}{$\begin{array}{l}\text { Baseline characteristics of all patients } \\
\qquad(n=95)\end{array}$} \\
\hline & Number & $\%$ \\
\hline \multicolumn{3}{|l|}{ Age at diagnosis } \\
\hline$<50$ years & 57 & 60 \\
\hline$\geq 50$ years & 38 & 40 \\
\hline \multicolumn{3}{|l|}{ Clinical tumor size } \\
\hline$<5 \mathrm{~cm}$ & 9 & 9.5 \\
\hline$\geq 5 \mathrm{~cm}$ & 86 & 90.5 \\
\hline \multicolumn{3}{|l|}{ Lymph node status } \\
\hline N0 & 19 & 20 \\
\hline $\mathrm{N} 1$ & 55 & 55.6 \\
\hline N2 & 21 & 22.1 \\
\hline \multicolumn{3}{|l|}{ Histologic grade } \\
\hline grade II & 65 & 68.4 \\
\hline grade III & 30 & 31.6 \\
\hline \multicolumn{3}{|l|}{ HmR Status } \\
\hline HmR positive & 74 & 77.9 \\
\hline HmR negative & 21 & 22.1 \\
\hline \multicolumn{3}{|l|}{ Her2/neu status } \\
\hline Her2/neu+ & 20 & 21.1 \\
\hline Her2/neu- & 75 & 78.9 \\
\hline \multicolumn{3}{|l|}{ P53 status } \\
\hline Inactive p53 & 29 & 31.5 \\
\hline Intact p53 & 66 & 69.5 \\
\hline Total & 95 & 100 \\
\hline
\end{tabular}

The majority of patients had grade II tumors (65 patients; $68.4 \%)$ and had large tumor size $(>5 \mathrm{~cm})$ (86 patients, (90.5\%), 19 patients of them had no palpable ipsilateral axillary nodes (N0), 55 patients had mobile ipsilateral axillary nodes (N1 disease), and only 21 patients had fixed nodes (N2 disease)). Seventy four patients had both ER and $\mathrm{PR}$ positive breast cancer. HER-2/neu positive staining was found in $20(21.1 \%)$ patients, and p53 inactivation in 29 (31.5\%) patients (Table 1$)$.

Out of the 95 patients, 68 patients $(71.6 \%)$ showed partial response and underwent CBS with negative margins and the remaining 27 patients underwent MRM. The association of clinical response and the findings of hormonal receptor, HER-2, and p53 protein were evaluated. The hormonal receptors were positive in $77.6 \%$ of patients with $\mathrm{OR}$ and in $78.9 \%$ of NR patients ( $P=1$; Fisher's exact test). There were no HER-2 and p53, protein expression significant differences before chemotherapy between the OR and NR groups ( $P=$ 0.345 and $P=0.096$, resp., Fisher exact test) (Table 2 ).

In terms of relapse following conservative surgery with negative margins ( 68 patients), 12 cases had a disease relapse (17.6), 4 of them had isolated local recurrence and were salvaged by mastectomy. Following MRM (27 patients), there were 7 disease relapses 3 of them were isolated relapse and were surgically resected (Table 3 ).
TABLE 2: Response of patients of locally advanced breast cancer to neoadjuvant chemotherapy according to biological prognostic factors.

\begin{tabular}{lccccc}
\hline Variable & $\begin{array}{c}\text { Objective response } \\
(n=76)\end{array}$ & \multicolumn{2}{c}{$\begin{array}{c}\text { No response } \\
(n=19)\end{array}$} & $P$ value \\
& Number & $\%$ & Number & $\%$ & \\
\hline HmR status & & & & & \\
$\quad \begin{array}{l}\text { HmR+ } \\
(n=74)\end{array}$ & 59 & 77.6 & 15 & 78.9 & 1 \\
$\quad \begin{array}{l}\text { HmR- } \\
(n=21)\end{array}$ & 17 & 22.3 & 4 & 21.1 & \\
$\begin{array}{c}\text { Her2/neo status } \\
\text { Her2/neo+ } \\
(n=20)\end{array}$ & 18 & 23.7 & 2 & 10.5 & 0.345 \\
$\begin{array}{c}\text { Her2/neo- } \\
(n=75)\end{array}$ & 58 & 76.3 & 17 & 89.5 & \\
p53 status & & & & & \\
$\begin{array}{l}\text { Inactive p53 } \\
(n=29)\end{array}$ & 20 & 26.3 & 9 & 47.4 & 0.096 \\
$\begin{array}{l}\text { Intact p53 } \\
(n=66)\end{array}$ & 56 & 73.7 & 10 & 52.6 & \\
\hline
\end{tabular}

TABLE 3: Pattern of disease relapse in all patients.

\begin{tabular}{lcccccc}
\hline \multirow{2}{*}{ Disease relapse } & \multicolumn{2}{c}{ CBS $(n=68)$} & \multicolumn{2}{c}{ MRM $(n=27)$} & \multicolumn{2}{c}{ Total $(n=95)$} \\
& Number & $\%$ & Number & $\%$ & Number & $\%$ \\
\hline LR & 4 & 5.9 & 3 & 11.1 & 7 & 7.3 \\
LR + DM & 1 & 1.5 & 2 & 7.4 & 3 & 3.2 \\
DM & 7 & 10.3 & 2 & 7.4 & 9 & 9.5 \\
\hline Total & 12 & 17.7 & 7 & 25.9 & 19 & 20 \\
\hline
\end{tabular}

The median follow-up period was 61 months (range 5665). The 5-year disease-free and overall survival rates were calculated for patients according to $\mathrm{HmR}$ status, Her2/neu expression, and p53 staining (Figures 1, 2, 3, 4, 5, and 6 ). The DFS rates at 5 years were $82.3 \%$ and $26.5 \%$ for breast cancer patients with positive and negative hormonal receptors, respectively $(P<0.0001$, HR 21.48, 95\% C.I.: 6.34-72.72), whereas the OAS rates were $84 \%$ and $35.7 \%$, respectively ( $P=0.0001$, HR 11.59 , 95\% C.I.: 3.32-40.47). The 5-year DFS rates were $33.8 \%$ and $81.8 \%$ for patients with Her2+ and Her2- breast cancer, respectively $(P<$ 0.0001, HR 12.27, 95\% C.I.: 3.92-38.42), and the 5-year OAS rates were $41.7 \%$ and $83.2 \%$, respectively $(P=0.001$, HR 7.14, 95\% C.I.: 2.21-23.06). For patients with inactive p53 and those with intact p53 breast cancer, the DFS rates were $46.1 \%$ and $83.6 \%$ respectively $(P=0.0007$, HR 5.15, 95\% C.I.: $1.99-13.33$ ), and OAS rates were $57.1 \%$ and $86.7 \%$ respectively $(P=0.0029$, HR 4.81, 95\% C.I.: $1.71-13.52)$ (Table 4).

Hormonal receptors were positive in 74 cases $(77.9 \%)$, where 72 cases $(97.3 \%)$ of these were HER-2 negative. On the other hand, 21 cases $(22.1 \%)$ were HR negative, 18 of them $(85.7 \%)$ were positive for Her-2 over-expression. Her2 over-expression was statistically significant associated with 


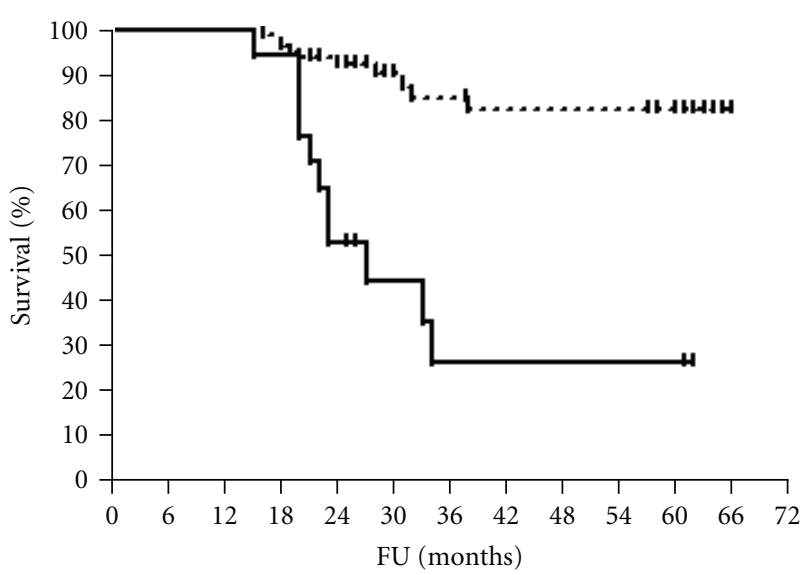

- $\mathrm{HmR}$ -

. t. $\mathrm{HmR}+$

FIGURE 1: DFS of patients according to HmR status.

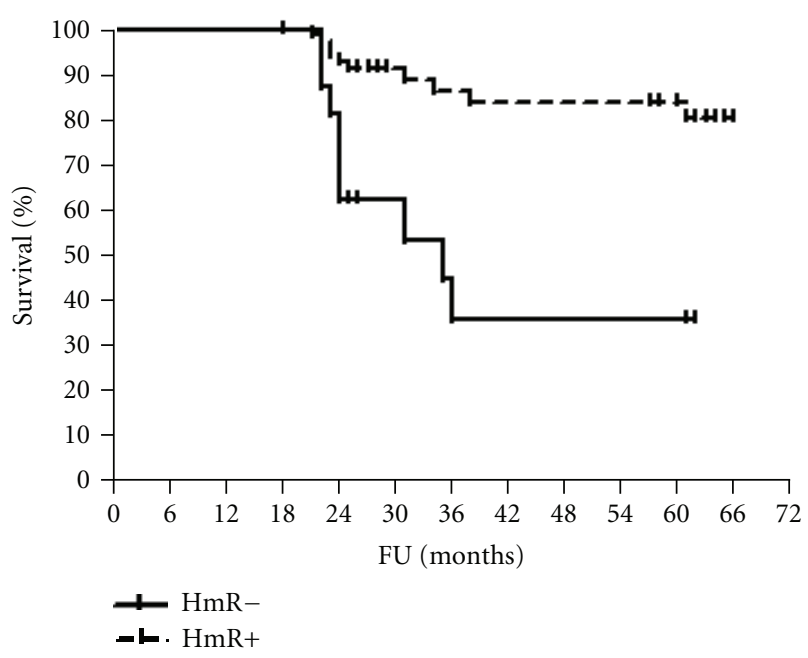

FIgURE 2: OAS of patients according to HmR status.

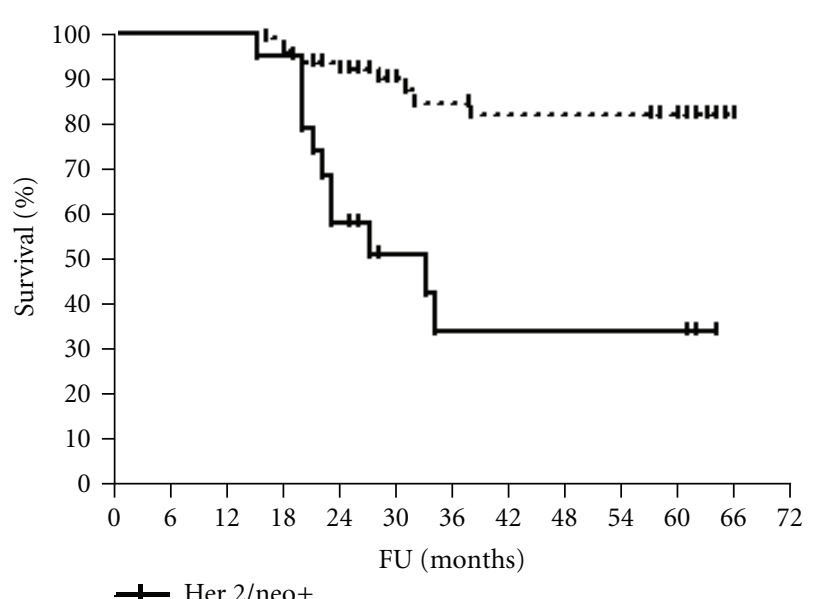

.4. . Her 2/neo-

FIGURE 3: DFS of patients according to Her2/neu status.

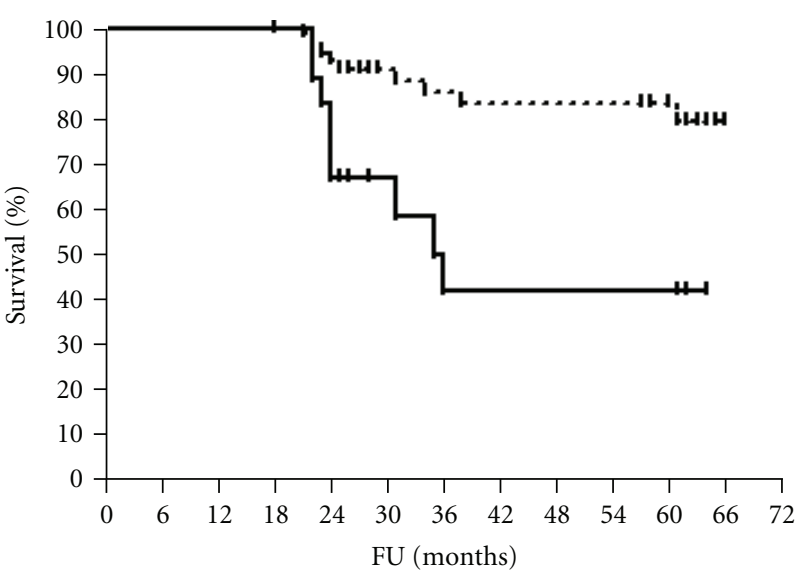

+ Her 2/neo+

at. . Her 2/neo-

FIGURE 4: OAS of patients according to Her2/neu status.

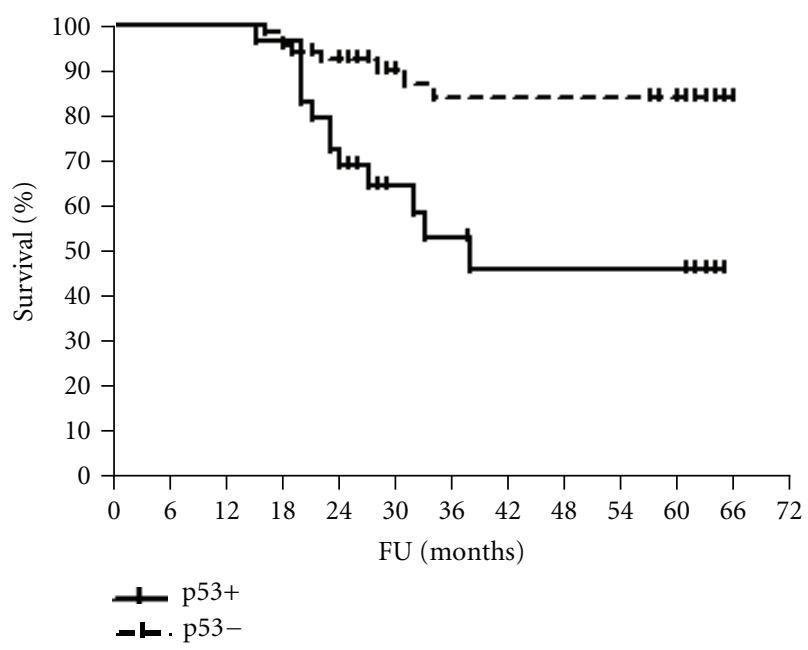

Figure 5: DFS of patients according to p53 status.

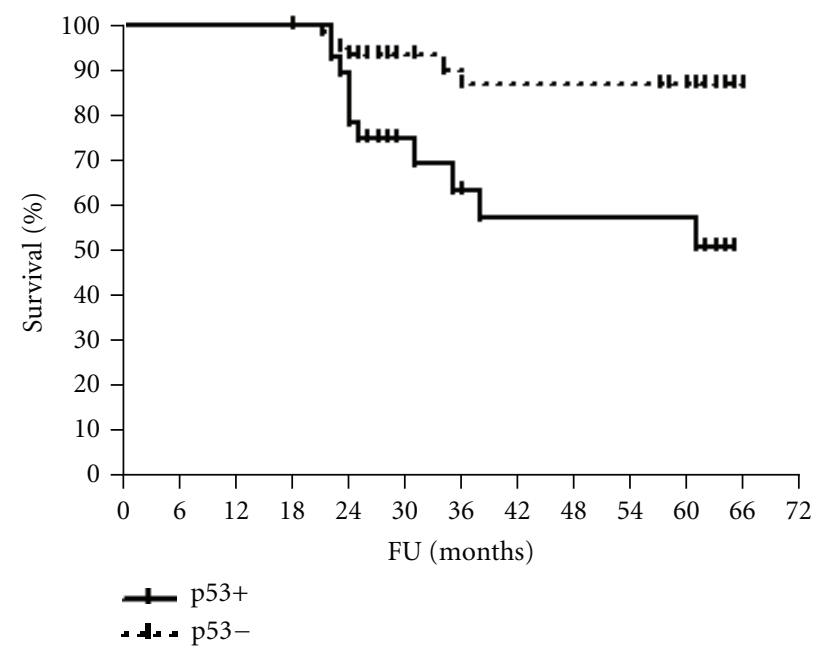

Figure 6: OAS of patients according to p53 status. 
TABLE 4: Five-year OAS and DFS rates in 95 breast cancer patients according to biological prognostic factors.

\begin{tabular}{|c|c|c|}
\hline Variable & $\begin{array}{c}\text { 5-year DFS rate } \\
(\%)\end{array}$ & $\begin{array}{c}5 \text {-year OAS rate } \\
(\%)\end{array}$ \\
\hline \multicolumn{3}{|c|}{$\begin{array}{l}\text { Hormonal receptor } \\
(\mathrm{HmR}) \text { status }\end{array}$} \\
\hline $\begin{array}{l}\mathrm{HmR}+ \\
(n=74)\end{array}$ & 82.3 & 84 \\
\hline $\begin{array}{l}\mathrm{HmR}- \\
(n=21)\end{array}$ & 26.5 & 35.7 \\
\hline$P$ value & $\begin{array}{c}P<0.0001 \\
\text { HR } 21.4895 \% \\
\text { CI } 6.34-72.72 \\
\end{array}$ & $\begin{array}{c}P=0.0001 \\
\text { HR } 11.59,95 \% \\
\text { CI } 3.32-40.47\end{array}$ \\
\hline \multicolumn{3}{|l|}{ Her2/neo status } \\
\hline $\begin{array}{l}\text { Her2/neo+ } \\
(n=20)\end{array}$ & 33.8 & 41.7 \\
\hline $\begin{array}{l}\text { Her } 2 / \text { neo- } \\
(n=75)\end{array}$ & 81.8 & 83.2 \\
\hline$P$ value & $\begin{array}{c}P<0.0001 \\
\text { HR } 12.27,95 \% \text { CI } \\
3.92-38.42 \\
\end{array}$ & $\begin{array}{l}P=0.001 \\
\text { HR } 7.14,95 \% \\
\text { CI 2.21-23.06 } \\
\end{array}$ \\
\hline \multicolumn{3}{|l|}{ p53 status } \\
\hline $\begin{array}{l}\text { Inactive p53 } \\
(n=29)\end{array}$ & 46.1 & 57.1 \\
\hline $\begin{array}{l}\text { Intact p53 } \\
(n=66)\end{array}$ & 83.6 & 86.7 \\
\hline$P$ value & $\begin{array}{l}P=0.0007 \\
\text { HR } 5.15,95 \% \\
\text { CI } 1.99-13.33\end{array}$ & $\begin{array}{c}P=0.0029 \\
\text { HR } 4.81,95 \% \\
\text { CI } 1.71-13.52\end{array}$ \\
\hline
\end{tabular}

loss of HmR positive immuno-staining $(P<0.0001)$, grade III breast cancer $(P<0.0001)$, advanced lymph node status $(P=0.0039)$, and patient $<50$ years of age $(P=0.0108)$ (Table 5). On the other hand, Her-2 over-expression was not statistically significant associated with p53 inactivation $(P=$ $0.412)$ and large tumor size $(\geq 5 \mathrm{~cm})(P=1)$.

With respect to biological features, all patients $(n=9)$ with inactive p53 and Her-2/neu coexpressing tumors and 8 out of 11 breast cancer patients $(72.7 \%)$ with Her2/neu expression and intact p53 were negative for hormonal receptors (Table 6).

\section{Discussion}

Identifying pretreatment factors that predict chemotherapy sensitivity would potentially allow for individually tailored chemotherapy. Using prognostic factor assessment to guide the selection of therapy has been explored with both adjuvant and neoadjuvant therapy regimens. Results have been discordant due to the heterogeneity of chemotherapy evaluated. Both taxanes and anthracycline have currently been used in neoadjuvant breast cancer treatment [17]. Investigations focusing on conventional markers did not allow to make valid predictions and were not able to find correlations between classical markers and response to taxanes and anthracyclines $[18,19]$. A wide variety of morphology-based
TABLE 5: Relation of Her 2/neu to p53, hormonal receptor status, grade, tumor size, lymph node status, and patients' age.

\begin{tabular}{|c|c|c|c|c|c|c|}
\hline \multirow[t]{2}{*}{ Variable } & \multirow[t]{2}{*}{ Number } & \multicolumn{2}{|c|}{$\begin{array}{c}\text { Her } 2 / \text { neu }+ \\
(n=20)\end{array}$} & \multicolumn{2}{|c|}{$\begin{array}{l}\text { Her2/neu- } \\
(n=75)\end{array}$} & \multirow[t]{2}{*}{$P$ value } \\
\hline & & Number & $\%$ & Number & $\%$ & \\
\hline \multicolumn{7}{|l|}{$\begin{array}{l}\text { Hormonal } \\
\text { receptor (HmR) }\end{array}$} \\
\hline $\mathrm{HmR}+$ & 74 & 2 & 2.7 & 72 & 97.3 & \multirow[t]{2}{*}{$<0.0001$} \\
\hline $\mathrm{HmR}-$ & 21 & 18 & 85.7 & 3 & 14.3 & \\
\hline \multicolumn{7}{|l|}{ p53 status } \\
\hline Inactive p53 & 29 & 8 & 27.6 & 21 & 72.4 & \multirow[t]{2}{*}{$=0.412$} \\
\hline Intact P53 & 66 & 12 & 18.2 & 54 & 81.8 & \\
\hline \multicolumn{7}{|l|}{ Grade } \\
\hline G II & 65 & 4 & 6.2 & 61 & 93.8 & \multirow[t]{2}{*}{$<0.0001$} \\
\hline G III & 30 & 16 & 53.3 & 14 & 47.7 & \\
\hline \multicolumn{7}{|l|}{ Tumor size } \\
\hline$<5 \mathrm{~cm}$ & 9 & 2 & 22.2 & 7 & 77.8 & \multirow[t]{2}{*}{$=1$} \\
\hline$\geq 5 \mathrm{~cm}$ & 86 & 18 & 20.1 & 68 & 79.9 & \\
\hline \multicolumn{7}{|l|}{$\begin{array}{l}\text { Lymph node } \\
\text { status }\end{array}$} \\
\hline N0 & 19 & 0 & 0 & 19 & 100 & \multirow{3}{*}{$=0.0039$} \\
\hline N1 & 55 & 11 & 20 & 44 & 80 & \\
\hline $\mathrm{N} 2$ & 21 & 9 & 42.9 & 12 & 57.1 & \\
\hline \multicolumn{7}{|l|}{ Age } \\
\hline$<50$ years & 57 & 17 & 29.8 & 40 & 70.2 & \multirow[t]{2}{*}{$=0.0108$} \\
\hline$\geq 50$ years & 38 & 3 & 7.9 & 35 & 92.1 & \\
\hline
\end{tabular}

and molecular-based breast cancer prognostic factors have been studied. An expanded understanding of the biology of breast cancer has led to the identification of the Her-2/neu receptor $[11,20]$ and p53 [21]. In the present study, the incidences of unfavorable biological tumor characteristics as negative hormonal receptors, Her2/neu overexpression, and inactive p53 were $18 \%, 20 \%$, and $31 \%$ respectively. These figures are comparable with those in the reported studies. $\mathrm{Li}$ et al. [22] have documented a prevalence of $21 \%$ of hormonal receptor negative breast cancer patients in US from 1992 to 1998. Her2/neu overexpression has been identified in $10 \%$ to $34 \%$ of patients with breast cancer [7, 23]. Mutations in the tumor suppressor gene p53 are present in $18 \%-25 \%$ of primary breast carcinomas [24].

The role of hormone receptor status as a predictive marker is less clear. In our study, negative hormonal receptors, expression of the Her-2 protein, and positive p53 staining were not able to predict the clinical tumor response. When it was evaluated in some trials of neoadjuvant chemotherapy, including docetaxel alone and doxorubicin followed by docetaxel, hormonal receptor status was not associated with clinical response [25]. Conversely, two clinical studies reported that negative hormonal receptor status was correlated with chemosensitivity $[26,27]$. The role of Her-2 as a predictive factor was studied $[28,29]$, where a correlation between Her-2 expression and response to neoadjuvant chemotherapy could not be observed in patients with breast 
TABLE 6: Coexpression of Her2/neu and p53 according to HmR status.

\begin{tabular}{lcccccc}
\hline variable & $\begin{array}{c}\text { Her2/neu+ and } \\
\text { inactive p53 }\end{array}$ & $\begin{array}{c}\text { Her2/neu- and } \\
\text { intact p53 }\end{array}$ & $\begin{array}{c}\text { Her2/neu+ and } \\
\text { intact p53 }\end{array}$ & $\begin{array}{c}\text { Her2/neu- and } \\
\text { inactive p53 }\end{array}$ & $\begin{array}{c}\text { Total } \\
P \text { value }\end{array}$ \\
\hline HmR+ & 0 & 51 & 3 & 20 & 74 \\
HmR- & 9 & 3 & 8 & 1 & 21 \\
\hline Total & 9 & 54 & 11 & 21 & 95 \\
\hline
\end{tabular}

carcinoma treated with 5-fluorouracil, doxorubicin, and cyclophosphamide combination (FAC regimen). In a metaanalysis of immunohistochemically evaluated p53 expression of more than 9000 breast cancer patients [30], the prognostic and predictive value of p53 overexpression appeared weak [31].

In the present study, the rate of isolated local recurrence was $7.3 \%$ (7 out of 95 patients). This is confirmed by a recent retrospective study conducted by Shen et al., [32] who investigated patients with T4 locally advanced breast cancer treated with 4 cycles of NAC. The actuarial breast cancer recurrence rate was rather low with $6 \%$.

The present study showed that the 5-year DFS and OAS rates of patients with hormonal receptor positive breast cancer were statistically significant and were higher than those in patients with negative hormonal receptors. These findings are confirmed by recent studies which have shown survival advantages among women with hormone receptors positive tumors relative to women with hormone receptor negative tumors [33-37].

Her2/neu overexpression is considered as a major prognostic factor in stage II and III breast cancer patients treated with neoadjuvant taxane, and anthracycline combination chemotherapy $[9,23,38-41]$. In the current study, there were statistically significant disease-free and overall survival advantages in patients with Her2 negative breast cancer in comparison with those in Her2 positive breast cancer patients. These results are reinforced by results of an Indian study [38]. Tiezzi et al. [39] reported that patients with Her2 positive tumors achieved an overall survival rate of $25 \%$ after 48 months in contrast with $70 \%$ in patients with Her2 negative expression. The 5-year DFS and OAS rates were significantly higher in p53 intact breast cancer patients than that in p53 inactive cancer patients, in the present study. This is in agreement with Gimenez et al. [42] but is in contrast to recent studies $[24,25]$, where overall survival and relapsefree survival rates were not independently predictive by $\mathrm{p} 53$ status in the overall patients group.

In the present study, Her2 overexpression was an associated feature of negative hormonal receptors, higher tumor grade, higher number of invaded axillary lymph nodes, and younger age at diagnosis. This is confirmed by many studies [40, 41, 43, 44]. Nieto et al. [43] demonstrated that alteration of Her2/neu is an associated feature of tumor aggressiveness as absence of hormonal receptors, advanced tumor stage, and young age at diagnosis. An inverse association had been found between Her-2/neu over-expression and the presence of receptors for steroid hormones (estrogen and progesterone) in both clinical correlative studies and experimental models [40]. Her-2/neu overexpression was significantly associated with tumor grade [41] and increasing number of involved axillary lymph nodes [44].

In contrast with the Rashed et al. [40], the present study did not show significant association between Her2 overexpression and tumor size. This could be explained by the higher proportion of large tumor size $(>5 \mathrm{~cm})$ in our study ( 86 out of 95 patients; $90.5 \%$ ) than that in the reported study (18 out of 50 patients; $36 \%$ ).

In the current study, inactive p53 and Her2/neu coexpressing tumors represented $9.5 \%$ ( 9 out of 95 patients) and were more often negative for hormonal receptors. This is comparable with the rate of breast cancer with coexpression reported in previous studies which ranged between $3 \%$ and $19.5 \%$ of total breast cancers examined $[10,45]$ and has been reported to be prognostically unfavorable [46].

In Conclusion we have found that the studied biological factors were not able to predict tumor response to neoadjuvant chemotherapy. However, Her2/neu overexpression was associated with poor disease-free and overall survival rates, which may be explained on the ground that it was significantly associated with negative hormonal receptors and high tumor grade.

\section{Abbreviations}

CBS: Conservative breast surgery

MRM: Modified radical mastectomy

Gys: Grays

Mev: Million electron volt

OAS: Over all survival

DFS: Disease free survival

NAC: Neoadjuvant chemotherapy

LABC: Locally advanced breast cancer

ER: Estrogen receptor

PR: Progesterone receptor

HmR: Hormonal receptor

HR: Hazard ratio

CI: Confidence interval

2D: Two dimensional

3 D: Three dimensional

LVEF: Left ventricular ejection fraction

ELISA: Enzyme linked immunosobent assay

$\mu \mathrm{L}: \quad$ Microlitre

\section{Conflict of Interests}

The authors declare that they have no conflict of interests. 


\section{Authors' Contribution}

M. I. El-sayed and D. W. Maximous carried out patients' selection, investigations, management, follow up, statistical analysis and drafting of the paper. M. M. Zakhary carried out ELISA technique for determination of biological markers. NNM participated in the followup of patients, statistical analysis and writing the final paper.

\section{References}

[1] M. Kaufmann, G. N. Hortobagyi, A. Goldhirsch et al., "Recommendations from an international expert panel on the use of neoadjuvant (primary) systemic treatment of operable breast cancer: an update," Journal of Clinical Oncology, vol. 24, no. 12, pp. 1940-1949, 2006.

[2] G. H. Ho, J. E. Calvano, M. Bisogna et al., "Genetic alterations of the p14ARF-hdm2-p53 regulatory pathway in breast carcinoma," Breast Cancer Research and Treatment, vol. 65, no. 3, pp. 225-232, 2001.

[3] W. H. EL Sawy, F. M. Abou Taleb, M. Abdel Kader et al., "Feasibility of breast conservation after neoadjuvant chemotherapy in 58 patients with locally advanced breast cancer using p53 and MDR1 genes as predictors of response," Journal of the Egyptian National Cancer Institute, vol. 14, no. 1, pp. 17-28, 2002.

[4] M. H. El-Didi, M. M. Moneer, H. M. Khaled, and S. Makarem, "Pathological assessment of the response of locally advanced breast cancer to neoadjuvant chemotherapy and its implications for surgical management," Surgery Today, vol. 30, no. 3, pp. 249-254, 2000.

[5] J. Y. Pierga, E. Mouret, V. Laurence et al., "Prognostic factors for survival after neoadjuvant chemotherapy in operable breast cancer: the role of clinical response," European Journal of Cancer, vol. 39, no. 8, pp. 1089-1096, 2003.

[6] P. Chollet, S. Amat, H. Cure et al., "Prognostic significance of a complete pathological response after induction chemotherapy in operable breast cancer," British Journal of Cancer, vol. 86, no. 7, pp. 1041-1046, 2002.

[7] P. N. Munster and L. Norton, "Predictive factor for the response to adjuvant therapy with emphasis in breast cancer," Breast Cancer Research, vol. 3, no. 6, pp. 361-364, 2001.

[8] W. F. Anderson, K. C. Chu, N. Chatterjee, O. Brawley, and L. A. Brinton, "Tumor variants by hormone receptor expression in white patients with node-negative breast cancer from the surveillance, epidemiology, and end results database," Journal of Clinical Oncology, vol. 19, no. 1, pp. 18-27, 2001.

[9] S. H. Giordano, "Update on locally advanced breast cancer," Oncologist, vol. 8, no. 6, pp. 521-530, 2003.

[10] A. Sidoni, A. Cavaliere, G. Bellezza et al., "Coexpression of HER-2/neu and p53 in breast cancer identifies a subset with an aggressive biopathological profile," Tumori, vol. 92, no. 5, pp. 412-415, 2006.

[11] D. J. -Slamon, G. M. Clark, S. G. Wong, W. J. Levin, A. Ullrich, and W. L. McGuire, "Human breast cancer: correlation of relapse and survival with amplification of the HER-2/neu oncogene," Science, vol. 235, pp. 177-182, 1987.

[12] J. Alsner, M. Yilmaz, P. Guldberg, L. L. Hansen, and J. Overgaard, "Heterogeneity in the clinical phenotype of TP53 mutations in breast cancer patients," Clinical Cancer Research, vol. 6, no. 10, pp. 3923-3931, 2000.
[13] S. W. Lowe, H. E. Ruley, T. Jacks, and D. E. Housman, "p53Dependent apoptosis modulates the cytotoxicity of anticancer agents," Cell, vol. 74, no. 6, pp. 957-967, 1993.

[14] O. H. Lowry, N. J. Rosebrough, A. L. Farr, and R. J. Randall, "Protein measurement with the Folin phenol reagent," The Journal of Biological Chemistry, vol. 193, no. 1, pp. 265-275, 1951.

[15] G. L. Miller, "Protein determination for large numbers of samples," Analytical Chemistry, vol. 31, no. 5, p. 964, 1959.

[16] R. J. Henry, D. C. Canon, and J. W. Winkelman, Clinical Chemistry: Principles and Techniques, 2nd edition, 1974.

[17] S. Goble and H. D. Bear, "Emerging role of taxanes in adjuvant and neoadjuvant therapy for breast cancer: the potential and the questions," Surgical Clinics of North America, vol. 83, no. 4, pp. 943-971, 2003.

[18] A. M. Gonzalez-Angulo, S. Krishnamurthy, Y. Yamamura et al., "Lack of association between amplification of her-2 and response to preoperative taxanes in patients with breast carcinoma," Cancer, vol. 101, no. 2, pp. 258-263, 2004.

[19] M. Coplin and M. Nauhton, "Clinical and pathologic predictors of complete pathologic response to neoadjuvant docetaxel/anthracycline chemotherapy in breast cancer patients," Journal of Clinical Oncology, vol. 22, no. 14, supplement, abstract 863, p. 85S, 2004.

[20] J. C. Sachdev and M. Jahanzeb, "Blockade of the HER family of receptors in the treatment of HER2- positive metastatic breast cancer," Clin Breast Cancer, vol. 12, no. 1, pp. 19-29, 2012.

[21] A. Degeorges, A. De Roquancourt, J. M. Extra et al., "Is p53 a protein that predicts the response to chemotherapy in node negative breast cancer?" Breast Cancer Research and Treatment, vol. 47 , no. 1 , pp. $47-55,1998$.

[22] C. I. Li, J. R. Daling, and K. E. Malone, "Incidence of invasive breast cancer by hormone receptor status from 1992 to 1998," Journal of Clinical Oncology, vol. 21, no. 1, pp. 28-34, 2003.

[23] J. S. Ross and J. A. Fletcher, "The HER-2/neu oncogene in breast cancer: prognostic factor, predictive factor, and target for therapy," Oncologist, vol. 3, no. 4, pp. 237-252, 1998.

[24] B. J. Chae, J. S. Bae, A. Lee et al., "p53 as a specific prognostic factor in triple-negative breast cancer," Japanese Journal of Clinical Oncology, vol. 39, no. 4, pp. 217-224, 2009.

[25] Z. Bo, Y. De-qi, and X. Fei, "Biological markers as predictive factors of response to neoadjuvant taxanes and anthracycline chemotherapy in breast carcinoma," Chinese Medical Journal, vol. 121, no. 5, pp. 387-391, 2008.

[26] H. D. Bear, S. Anderson, A. Brown et al., "The effect on tumor response of adding sequential preoperative docetaxel to preoperative doxorubicin and cyclophosphamide: preliminary results from National Surgical Adjuvant Breast and Bowel Project Protocol B-27," Journal of Clinical Oncology, vol. 21, no. 22, pp. 4165-4174, 2003.

[27] M. Colleoni, G. Viale, D. Zahrieh et al., "Chemotherapy is more effective in patients with breast cancer not expressing steroid hormone receptors: a study of preoperative treatment," Clinical Cancer Research, vol. 10, no. 19, pp. 6622-6628, 2004.

[28] F. Zhang, Y. Yang, T. Smith et al., "Correlation between HER-2 expression and response to neoadjuvant chemotherapy with 5fluorouracil, doxorubicin, and cyclophosphamide in patients with breast carcinoma," Cancer, vol. 97, no. 7, pp. 1758-1765, 2003.

[29] M. Fernández-Sánchez, A. Gamboa-Dominguez, N. Uribe et al., "Clinical and pathological predictors of the response to neoadjuvant anthracycline chemotherapy in locally advanced breast cancer," Medical Oncology, vol. 23, no. 2, pp. 171-183, 2006. 
[30] A. Honig, L. Rieger, M. Sutterlin, D. Wallwiener, J. Dietl, and E. Solomayer, "State of the art of neoadjuvant chemotherapy in breast cancer: rationale, results and recent developments," German Medical Science, vol. 3, 2005.

[31] S. Rozan, A. Vincent-Salomon, B. Zafrani et al., "No significant predictive value of c- erbB-2 or p53 expression regarding sensitivity to primary chemotherapy or radiotherapy in breast cancer," International Journal of Cancer, vol. 79, pp. 27-33, 1998.

[32] J. Shen, V. Valero, T. A. Buchholz et al., "Effective local control and long-term survival in patients with T4 locally advanced breast cancer treated with breast conservation therapy," Annals of Surgical Oncology, vol. 11, no. 9, pp. 854-860, 2004.

[33] P. B. Fisher, J. H. Jeong, P. J. Bryant et al., "Treatment of lymph-node-negative, oestrogen-receptor-positive breast cancer: long-term findings from National Surgical Adjuvant Breast and Bowel Project randomised clinical trials," The Lancet, vol. 364, no. 9437, pp. 858-868, 2004.

[34] V. R. Grann, A. B. Troxel, N. J. Zojwalla, J. S. Jacobson, D. Hershman, and A. I. Neugut, "Hormone receptor status and survival in a population-based cohort of patients with breast carcinoma," Cancer, vol. 103, no. 11, pp. 2241-2251, 2005.

[35] L. K. Dunnwald, M. A. Rossing, and C. I. Li, "Hormone receptor status, tumor characteristics, and prognosis: a prospective cohort of breast cancer patients," Breast Cancer Research, vol. 9, no. 1, article R6, 2007.

[36] J. A. Zell, W. Y. Tsang, T. H. Taylor, R. S. Mehta, and H. AntonCulver, "Prognostic impact of human epidermal growth factor-like receptor 2 and hormone receptor status in inflammatory breast cancer (IBC): analysis of 2,014 IBC patient cases from the California Cancer Registry," Breast Cancer Research, vol. 11, no. 1, article R9, 2009.

[37] H. G. Kaplan and J. A. Malmgren, "Impact of triple negative phenotype on breast cancer prognosis," Breast Journal, vol. 14, no. 5, pp. $456-463,2008$.

[38] V. Kumar, M. Tewari, U. Singh, and H. S. Shukla, "Significance of Her-2/neu protein over expression in Indian breast cancer patients," Indian Journal of Surgery, vol. 69, pp. 122-128, 2007.

[39] D. G. Tiezzi, J. M. Andrade, A. Ribeiro-Silva, F. E. Zola, H. R. C. Marana, and M. G. Tiezzi, "HER-2, p53, p21 and hormonal receptors proteins expression as predictive factors of response and prognosis in locally advanced breast cancer treated with neoadjuvant docetaxel plus epirubicin combination," $B M C$ Cancer, vol. 7, article 36, 2007.

[40] M. M. Rashed, N. M. Ragab, and M. K. Galal, "The association of HER-2/neu over-expression in relation to p53 nuclear accumulation, hormonal recceptor status and common clinicopathological prognostic parameters in a series of Egyptian women with invasive ductal carcinoma," European Journal of General Medicine, vol. 4, no. 2, pp. 73-79, 2007.

[41] H. Swede, K. B. Moysich, J. S. Winston et al., "Variation of the prognostic significance of HER-2 expression in breast cancer according to tumor size," Breast Journal, vol. 9, no. 2, pp. 98$105,2003$.

[42] L. Gimenez, A. Alvarez, E. Mickiewicz et al., "Tumor Biology and Human Genetics," abstract no. 2434, 1999.

[43] Y. Nieto, P. J. Cagnoni, S. Nawaz et al., "Evaluation of the predictive value of Her-2/neu overexpression and p53 mutations in high-risk primary breast cancer patients treated with high-dose chemotherapy and autologous stem-cell transplantation," Journal of Clinical Oncology, vol. 18, no. 10, pp. 20702080, 2000.

[44] T. Fusun, A. Semsi, U. Cem et al., "Association of HER-2/neu overexpression with the number of involved axillary lymph nodes in hormone receptor positive breast cancer patients," Experimental Oncology, vol. 27, no. 2, pp. 145-149, 2005.

[45] S. B. Bull, H. Ozcelik, D. Pinnaduwage et al., "The combination of p53 mutation and neu/erbB-2 amplification is associated with poor survival in node-negative breast cancer," Journal of Clinical Oncology, vol. 22, no. 1, pp. 86-96, 2004.

[46] I. Guerra, J. Algorta, R. Díaz De Otazu, A. Pelayo, and J. Fariña, "Immunohistochemical prognostic index for breast cancer in young women," Journal of Clinical Pathology, vol. 56, no. 6, pp. 323-327, 2003. 


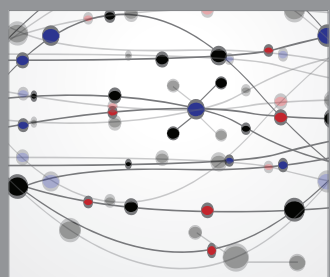

The Scientific World Journal
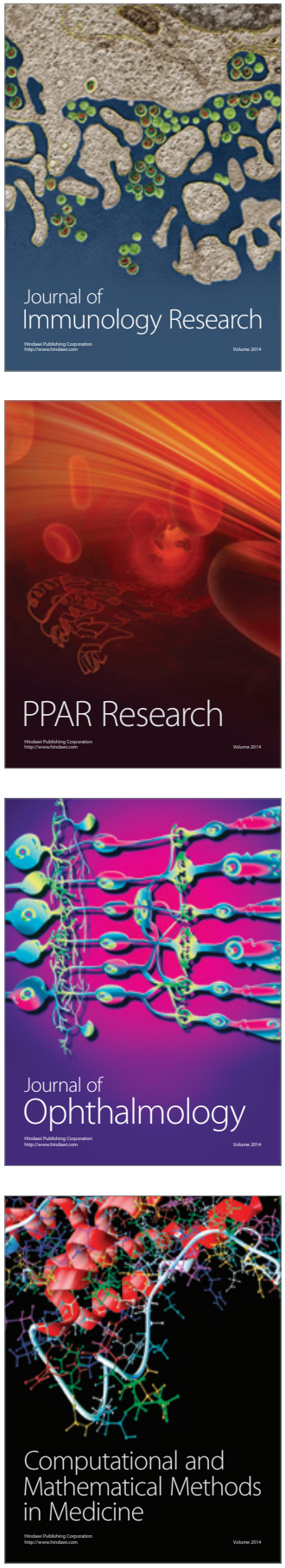

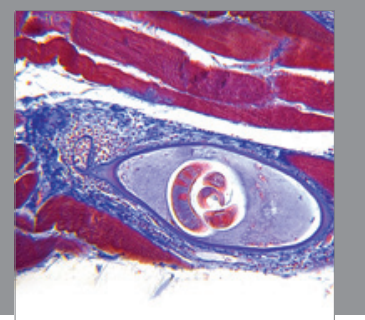

Gastroenterology

Research and Practice
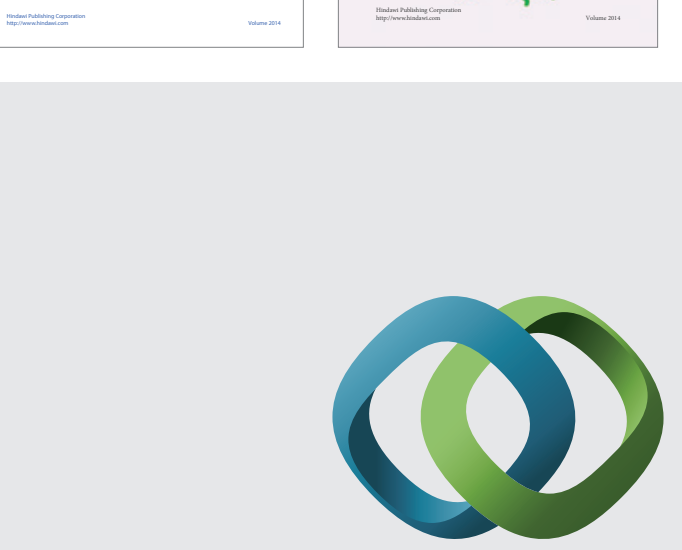

\section{Hindawi}

Submit your manuscripts at

http://www.hindawi.com
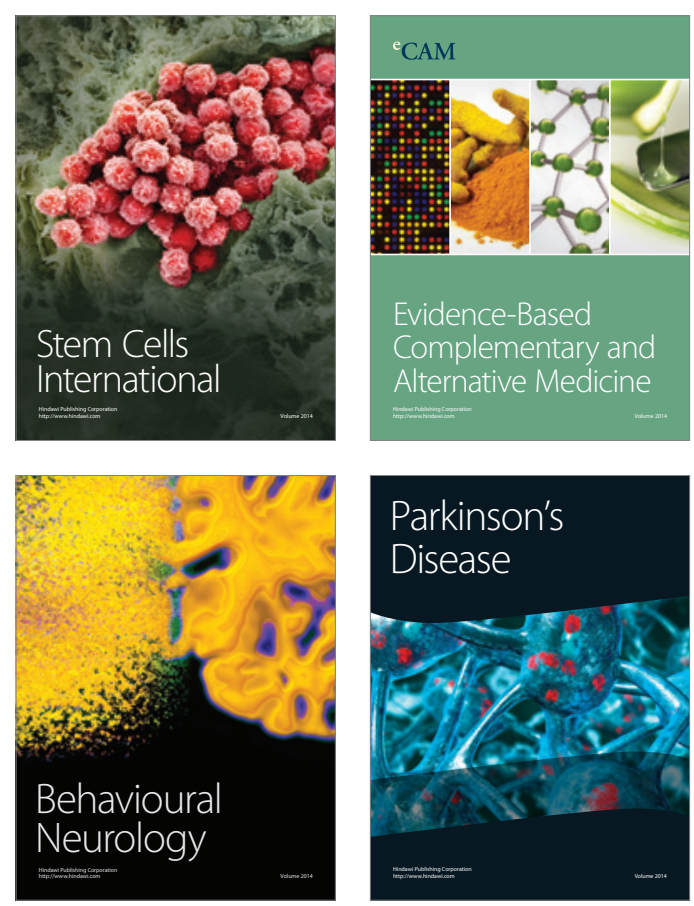

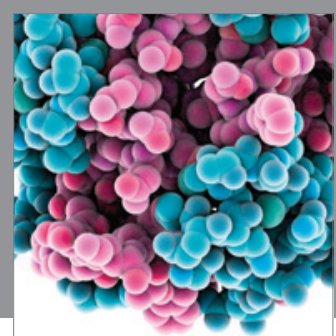

Journal of
Diabetes Research

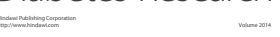

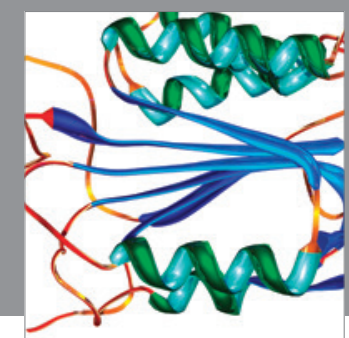

Disease Markers
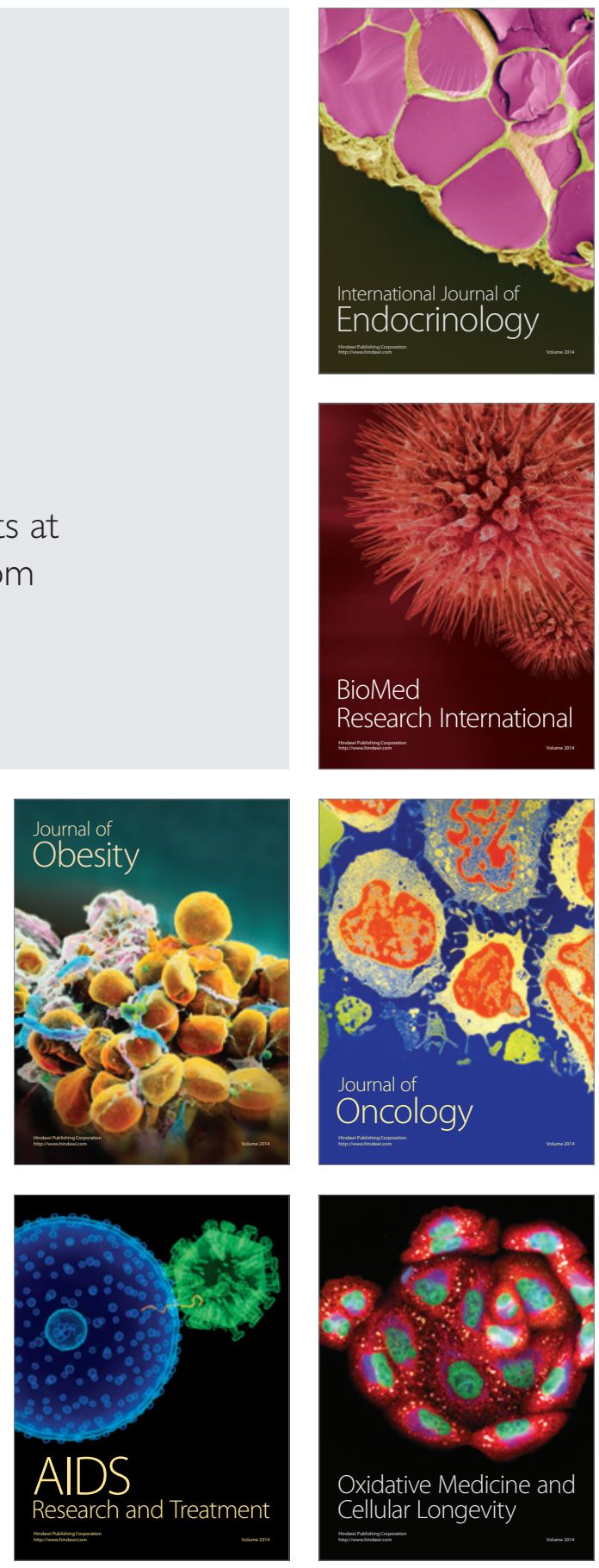